\title{
Posterior Tooth Size, Body Size, and Diet in South African Gracile Australopithecines ${ }^{1}$
}

\author{
MILFORD H. WOLPOFF \\ Department of Anthropology, University of Michigan, Ann Arbor, \\ Michigan 48104
}

KEY WORDS Australopithecus - Tooth size - Body size - Diet.

\begin{abstract}
A model relating relative size of the posterior teeth to diet is suggested for forest and savanna primates and Homo. Relative tooth size is calculated for the South African gracile australopithecine sample using posterior maxillary area sums and size estimates based on four limb bones. A number of limbs were shown to be non-hominid. Comparisons show the South African gracile sample apparently adapted to a very heavily masticated diet with relative tooth size significantly greater than any living hominoid. Periodic intensive utilization of grains and roots combined with scavenged animal protein are suggested as the most likely dietary reconstruction.
\end{abstract}

The purpose of this work is to examine the dietary inferences made possible by considering certain characteristics of South African gracile australopithecine dentitions. By gracile australopithecine, I specifically refer to the South African Lower Pleistocene specimens which have been assigned to the taxon "Australopithecus africanus." This taxon comprises all of the specimens from Sterkfontein, Makapansgat, and Taung.

\section{A FUNCTIONAL MEASURE OF TOOTH SIZE}

Under certain conditions, tooth size can be used as one indicator of diet (Wolpoff, '71c). The surfaces of the posterior teeth (P3-M3) provide most of the area available for mastication (Wolpoff, '71b, table 1). The sum of the surface areas of the posterior teeth therefore gives an indication of the total masticatory area maintained by selection. The masticatory area necessary is a function of two variables: the amount of food necessary to maintain a given body size; and the physical consistency of the food eaten. If body size is taken into account, the sum of the posterior areas best relates to the nutritional value and physical consistency of the food eaten. Within limits, then, relative posterior tooth size can be used to reconstruct dietary information.

In many primates, the anterior teeth are used in gathering and preparing food, and could possibly be used as another source of dietary information. For culture-bearing hominids, the situation is somewhat more problematical because even simple tools probably replace or supplement the anterior teeth in these functions while the anterior dentition has an additional important function - environmental manipulation not directly associated with food. Thus, because the contribution of the anterior dentition to dietary reconstruction is ambiguous, and it does not contribute significantly to the surface area available for mastication, I will be concerned solely with the posterior dentition.

There are two possible objections to the use of surface area to reconstruct diet. First, groove and cusp patterns are ignored. The surface topology, however, seems more closely related to spacing the incomplete dentition along the arch, and is worn away by maturity in hominid populations under intense selection for large tooth size. For most of the life of a tooth in such a population, there is no groove or cusp pattern. In samples such as the australopithecine collection considered here, the wear rate of individual teeth is so rapid that the surface topology is lost within a few years of eruption. For most of an individual's life span, whatever the length, most of the teeth are

\footnotetext{
1 This research was supported by NSF grant GS-33035.
} 
TABLE 1

All postcranial remains from South Africa which have been designated as possible graciles The attributions suggested are the result of comparisons with known hominid and non-hominid material at the Transvaal museum and the Department of the Anatomy of the University of the Witwatersrand. These attributions were discussed with C. K. Brain, A. Hughes, and A. Walker. Of these specimens, the only bones likely to belong to the same individual are the set designated as STS 14, the humerus, scapula, and mandible of STS 7, and possibly MLD 7 and 8.

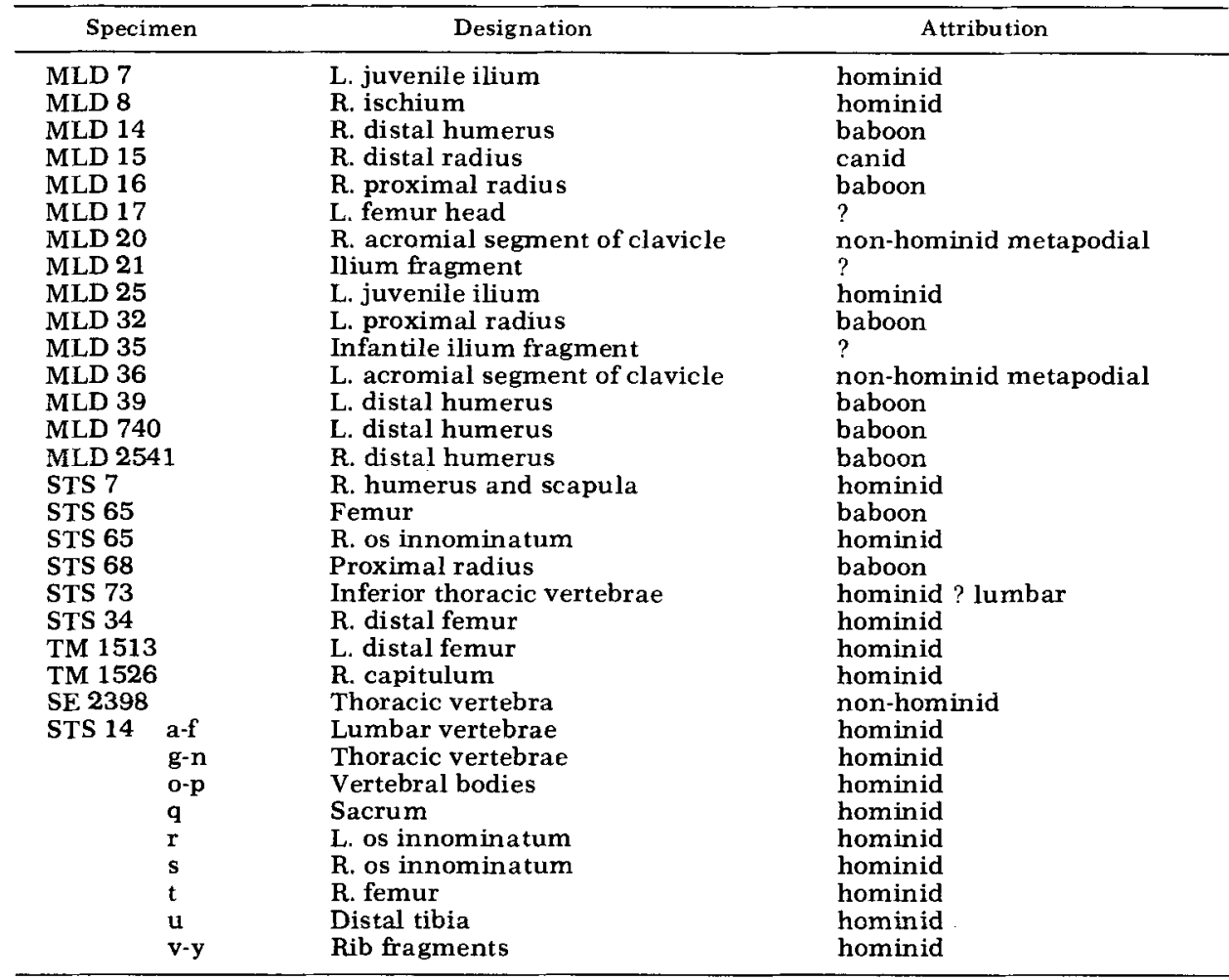

worn enough so that little if any of the original surface remains. Second, I have used the surface area rather than the volume as a measure of available grinding area. A volume estimate could be obtained by multiplying each surface area by crown height. However, while this might measure the total amount of grinding area that will ultimately be available, it does not estimate the grinding area at one specific time. The total amount of area that will eventually become available complicates the study by adding another variable, the lifespan of the animal. In addition, a volume estimate would reduce the size of the available gracile australopithecine sample to almost nothing by restricting the sample to individuals with unworn full posterior dentitions.

Consequently, the summed areas of the posterior teeth are used as a functional measure of diet. In order to allow comparisons of hominids and the African apes, the maxilla is used. $P_{3}$ functions in conjunction with the upper canine in the living apes, and does not act as one of the grinding teeth as it does in hominids. $\mathrm{P}^{3}$, on the other hand, functions as a grinding tooth in both pongids and hominids.

\section{PRIMATE DIETS AND POSTERIOR TOOTH SIZE}

Among the living primates there is great variation in diet (Lee, '68; Altmann and Altmann, '70; Jones and Pi, '71). Chimpanzees and gorillas provide a model for tooth size variation in vegetarian hominoids. Of course, the diets of these two apes are not identical. In a comparative ecology recently published by Jones and Pi (71), 
gorillas were found to be more herbivorous than frugivorous, feeding either on the ground or near it. Chimpanzees were more frugivorous but also partly herbivorous and carnivorous (Teleki, '73).

In terms of the masticatory requirements of the diet, chimpanzees present a minimum model for the prediction of tooth size. That is, their teeth are about as small as could be expected in vegetarian primates, relative to body size. Summed maxillary posterior areas in chimpanzees indicate tooth size in a fruit-eating pongid which also utilizes leaves, nuts, bark, seeds, and meat. Gorillas, whether or not sympatric with chimpanzees, show a clear preference for the vascular part of broad-leafed plants. Eating the stems, leaves, and pith requires heavier mastication than is necessary in the fruit-preferring chimpanzee. Their relative size is maximum for the African forest-dwelling apes.

Gorilla females weigh from 165 to 240 pounds, and males from 300 to 400 pounds, according to Napier and Napier ('67). Data from Schaller ('63) indicates average male and female weights for wild lowland gorillas of 375 and 198 pounds. An average of 286 pounds $(130 \mathrm{~kg}$ ) will be used here. Napier and Napier ('67) report average chimpanzee male and female body weights of 110 and 90 pounds, and weights of 95 and 75 pounds are reported by Rahm ('67). The average value of 92.5 pounds $(42 \mathrm{~kg}$ ) will be used here. Modern Homo sapiens, with an average body size roughly $50 \%$ greater than the chimpanzee, and population averages ranging from chimpanzee size to $100 \%$ larger, is dentally adapted to an omnivorous diet incorporating more extensively prepared foods (Lee, '68). Neandertals, or Homo erectus, can be used to indicate relative tooth size in an omnivorous hominid with less food preparation.

Jolly (70a) points out that unlike the African pongids, the niches occupied by the African cercopithecoids grade out on to the savanna. At the extreme, as the climate becomes drier, the cercopithecoid diet includes a greater percentage of grasses, seeds, and other small hard objects (Altmann and Altmann, '70). That is, as the savanna becomes increasingly arid, cercopithecoids utilize foods which yield less nutritional energy per amount of energy expended in mastication. As a result, ge- lada baboons have numerous adaptations to a heavily masticated diet, including expanded posterior teeth. Recently, Jolly (70b) has shown that the same adaptive complex characterized the apparently terrestrial fossil lemur genus Hadropithecus in contrast to the more semiterrestrial fossil genus Archaeolemur.

Jolly suggests that this baboon model can be applied to early hominids, hypothesizing a seed-eater stage of early hominid evolution. It should be expected that a hominid occupying a savanna niche and utilizing heavily masticated foods will have posterior teeth relatively larger than those of the African apes. Homo sapiens is the only living hominoid with savanna-adapted populations. Compared with the other hominoids, his posterior dentition does not fit the cercopithecoid model, since the African apes have a relatively larger dentition than modern man. The discrepancy seems due to the large quantities of meat and the extensive culturally determined preparation of plant foods in the diet of modern savanna-adapted human populations. Jolly suggests that there was an earlier stage of hominid savanna adaptation with limited food preparation and restricted meat intake. For this stage, one would expect the masticatory apparatus to approximate more closely ecological variation in the ground-dwelling cercopithecoids.

In sum, the living African apes and modern man represent the range of relative tooth size variation for living hominoids. As such, they are a logical basis of comparison for the South African fossils. Jolly's seed-eater hypothesis, based on a baboon analogy, predicts a posterior dentition for hominids in the seed-eater stage relatively larger than any of the living hominoids. A number of workers have suggested that the robust australopithecines conform to Jolly's predictions. I propose to determine whether the South African gracile australopithecine sample also fits this model. It will be neces sary to discuss first the estimation of body size, and then to calculate posterior tooth size. Finally, relative posterior tooth size can be compared with the living hominoids.

\section{GRACILE AUSTRALOPITHECINE BODY SIZE}

Determination of relative tooth size de- 
pends on a knowledge of body size. Published estimates of average body size for the South African gracile sample range from 23 to $36 \mathrm{~kg}$. These are usually based on STS 14, the most complete postcranial skeleton of any australopithecine. However, there are a number of other postcranial bones available, and the best estimate of range and average should utilize all possible information.

\section{(a) Available material}

Table 1 reviews all of the specimens which have been considered hominid. Careful comparative inspection has revealed that many of the supposed hominids were actually baboons. Most comparative work concerning the australopithecines has utilized the African pongids in attempts to show the hominid nature of the remains. However, the actual sorting problem at the cave sites comes from baboons which have many postcranial bones of similar size and, when fragmented, often similar morphology. In judging the attributions presented in table 1, I did not settle on an identification unless I could match the questionable fragment with the corresponding body part of the non-hominid in question. Most of the confusion has been with baboons. This is especially true of the forelimbs. For instance, the only hominid proximal radius is from Swartkrans, SK 18. One distal radius, MLD 15, is non-primate and best matches a canid. The two Makapansgat clavicular fragments are metapodials of a nonprimate. There are several fragments I could not identify at all. Of these, the most important is MLD 17, a portion of a femur head. This specimen may be hominid, but presents a very unusual morphological configuration of epiphyseal line and extremely widened and depressed fovea which I cannot duplicate in any known hominid. The head is too large to belong to a baboon. MLD 21 and 35 are too small and fragmentary to identify accurately. This leaves ten hominid specimens.

Of these ten, I have questioned the designation of one. STS 73 has been reported as an immature eleventh or twelfth thoracic vertebra (Robinson, '70). The specimen consists of most of the centrum and the anterior border of the neural canal. I can find no convincing evidence of a rib articular facet on the body; there is no raised and smoothed articular surface. What appears instead is a roughened, somewhat circular hollow on the posterior superior half of the right side, with an indefinite rim about it. There are no other identifying features. The heart-shape of the centrum in superior view appears very much like STS 14e. The articular facet on the lower thoracics of STS 14 and on the Swartkrans terminal thoracic SK $3981 \mathrm{a}$ is clearly raised above the surrounding surface and flattened. Consequently, I believe that STS 73 could be a lumbar vertebra.

\section{(b) Direct estimates and comparisons}

The best individual size estimate comes from STS 14, which has an almost complete vertebral column including the lower 15 vertebrae, most of the pelvis, and the proximal end of the right femur. That the individual was extremely small is apparent from comparisons with the limbs of pygmies and other very small modern individuals reported by Broek ('38).

Using Robinson's reconstruction of the STS 14 pelvis pictured by Day ('65), the distal femur fragments from Sterkfontein (STS 34, TM 1513), and the proximal femur fragments from Swartkrans (SK 82, 97), Lovejoy and Heiple ('70) reconstruct the STS 14 femur with a length of $276 \mathrm{~mm}$. When their method was applied to a small sample of Homo sapiens femurs of known length, the average error was about $20 \%$ of the actual value, and the estimate for STS 14 should be considered with this in mind. My measurements on the original specimens closely conform to those used by Lovejoy and Heiple. This is especially true for interacetabular breadth, a crucial component of their reconstruction. STS $14 \mathrm{r}$ includes a portion of the pubis which extends past the midline, making a symmetric reconstruction of the pelvis possible by reconstructing the missing pubic area in STS 14s. The interacetabular distance measured in my reconstruction is $102 \mathrm{~mm}, 1$ $\mathrm{mm}$ less than the value employed by Lovejoy and Heiple. The biomechanical neck length they used is a minimum value. The entire head of STS $14 \mathrm{t}$ is reconstructed. The size reconstruction is accurate, limited as it is by the size of the acetabulum. However, the head was placed at the broken end of the neck. At this break, there is no evidence of epiphyseal line or neck 
termination, so the neck, and consequently the biomechanical neck length, could be somewhat longer. Thus, their estimate should be taken as a minimum. Robinson (72: 125) rejects the Lovejoy and Heiple ('50) estimate on the grounds that his calculation of bicondylar angle, when applied to their method, would indicate an estimated femur length of about $400 \mathrm{~mm}$. Robinson's value for the bicondylar angle of TM 1513 is $9^{\circ}$, almost identical to Le Gros Clark's value of $7^{\circ}$ (47), and quite different from the $14^{\circ}$ determination made by Lovejoy and Heiple. The method of angle determination utilized by these authors is not the same as that applied by Le Gros Clark ('47). It was chosen as the most appropriate means of estimating the angulation of the entire femur shaft with the vertical. While Robinson does not indicate which procedure he used to calculate the bicondylar angle, the $9^{\circ}$ value suggests that the Lovejoy and Heiple method was not used. This suggestion is further indicated by the fact that the Lovejoy and Heiple (70) paper was written after Robinson's chapter on the femur (see p. 125). Consequently, it does not seem reasonable to apply data derived by an inappropriate method to invalidate Lovejoy and Heiple's reconstruction. Robinson further suggests a considerably longer dimension for STS 14 because $276 \mathrm{~mm}$ would leave only $5 \mathrm{~mm}$ between STS 14 and the remaining portion of TM 1513. In his view, $5 \mathrm{~mm}$ is too short for the transition from a linea on STS 14 to supracondylar lines separated by $15 \mathrm{~mm}$ which occur on TM 1513. This argument, however, assumes equal dimensions for the two specimens in an attempt to show that STS 14 was likely as long as TM 1513, and is apparently circular. In sum, there is no reason not to accept the results of the Lovejoy and Heiple reconstruction.

Because of the pubic area present on STS 14r, it is possible to sex the specimen. The subpubic angle is very wide and there is a definite ventral arc. The surface is very narrow below the symphysis. These data indicate the specimen is female.

There are three other innominates STS 14 can be compared with: two juveniles with unfused ilia from Makapansgat and the second adult from Sterkfontein. Metric comparisons are shown in table 2. The second Sterkfontein specimen, STS 65, has a much stronger pilaster but also has a preauricular sulcus, raising the possibility that it too belongs to a female specimen. Because of the broken condition of the STS 65 ilium, most comparisons are limited to breadths and thicknesses. As the table indicates, the two Sterkfontein adults are very similar in size, although STS 65 is more robustly developed. Thus, there are two individuals of roughly similar size at Sterkfontein, both possibly female.

The other direct comparison that can be made is in the vertebrae. STS 73 is compared with the lumbar vertebrae of STS 14 in table 3. STS 73 is larger than all of the STS 14 lumbars. The table also indi-

TABLE 2

Comparative measures possible for South African gracile australopithecine innominates. The Sterkfontein specimens are adults. The Makapansgat specimens are younger than 13-15, since the primary elements of the innominate are unfused, although fusion of the anterior inferior spine is complete. All measurements are in millimeters

\begin{tabular}{lccccc}
\hline & $\begin{array}{c}\text { STS } \\
14 \mathbf{r}\end{array}$ & $\begin{array}{c}\text { STS } \\
14 \mathrm{~s}\end{array}$ & $\begin{array}{c}\text { STS } \\
65\end{array}$ & $\begin{array}{c}\text { MLD } \\
7\end{array}$ & $\begin{array}{c}\text { MLD } \\
25\end{array}$ \\
\hline $\begin{array}{l}\text { Anterior inferior to posterior } \\
\text { inferior spines }\end{array}$ & & 82.0 & 84.0 & 67.5 & 70.0 \\
$\begin{array}{l}\text { Posterior inferior spine to the } \\
\text { notch between the anterior spines }\end{array}$ & 81.0 & 79.0 & 76.5 & 69.0 & 70.0 \\
$\begin{array}{l}\text { Minimum distance from the greater } \\
\text { sciatic notch to the notch between } \\
\text { the anterior spines }\end{array}$ & & 45.0 & 47.0 & 41.0 & 42.0 \\
$\begin{array}{l}\text { Minimum ilium thickness } \\
\begin{array}{l}\text { Maximum pilaster thickness } \\
\hline\end{array}\end{array}$ & 3.6 & 3.0 & 1.1 & 4.0 & 2.0 \\
\hline
\end{tabular}


TABLE 3

Comparison of STS 73 with the lumbar vertebrae of STS 14. All measurements are in millimeters

\begin{tabular}{|c|c|c|c|c|c|c|c|}
\hline & $\begin{array}{l}\text { STS } \\
73\end{array}$ & $\begin{array}{l}\text { STS } \\
14 \mathrm{a}\end{array}$ & $\begin{array}{l}\text { STS } \\
14 b\end{array}$ & $\begin{array}{l}\text { STS } \\
14 \mathrm{c}\end{array}$ & $\begin{array}{l}\text { STS } \\
14 \mathrm{~d}\end{array}$ & $\begin{array}{l}\text { STS } \\
14 \mathrm{e}\end{array}$ & $\begin{array}{l}\text { STS } \\
14 f\end{array}$ \\
\hline $\begin{array}{l}\text { Dorsal cranial-caudal } \\
\text { thickness }\end{array}$ & 21.3 & 16.5 & 17.4 & 19.3 & 19.6 & 20.3 & 19.9 \\
\hline $\begin{array}{l}\text { Ventral cranial-caudal } \\
\text { thickness }\end{array}$ & 19.8 & 19.5 & 18.7 & 19.7 & 20.0 & 19.5 & 18.5 \\
\hline $\begin{array}{l}\text { Maximum dorsal-ventral } \\
\text { cranial length of } \\
\text { centrum }\end{array}$ & 24.3 & 19.5 & 17.5 & 20.2 & 20.2 & 20.5 & \\
\hline $\begin{array}{l}\text { Minimum dorsal-ventral } \\
\text { cranial length of } \\
\text { centrum }\end{array}$ & 20.6 & 18.6 & 17.5 & 18.5 & 19.0 & 17.8 & \\
\hline $\begin{array}{l}\text { Minimum dorsal-ventral } \\
\text { caudal length of } \\
\text { centrum }\end{array}$ & 21.0 & 16.9 & 18.3 & 18.6 & 18.0 & 17.9 & 17.9 \\
\hline $\begin{array}{l}\text { Cranial breadth of } \\
\text { centrum }\end{array}$ & 32.0 & 24.9 & & 27.0 & 23.5 & 24.1 & \\
\hline $\begin{array}{l}\text { Breadth of neural } \\
\text { canal }\end{array}$ & 16.8 & 19.4 & 13.2 & 12.9 & 13.5 & 13.4 & 13.4 \\
\hline $\begin{array}{l}\text { Cranial surface area } \\
\text { as a per cent of } \\
\text { STS } 73\end{array}$ & & 70.0 & & 76.0 & 67.5 & 65.0 & \\
\hline $\begin{array}{l}\text { Volume estimate as } \\
\text { a per cent of STS } 73\end{array}$ & & 61.5 & & 72.0 & 65.0 & 63.0 & \\
\hline
\end{tabular}

cates the percentage of estimated surface area and volume for STS $14 \mathrm{a}, \mathrm{c}, \mathrm{d}$, and e compared with STS 73 . These range from $65 \%$ to $76 \%$ for surface area and $61.5 \%$ to $72 \%$ for volume. If STS 73 is a lumbar, it represents a considerably larger individual than STS 14. If, instead, it is an immature thoracic, the individual is larger yet. Whatever the case, an individual considerably larger than STS 14 is indicated by this direct comparison. It is possible that the considerably larger individual is male.

No other direct comparisons can be made. Consequently, the remaining three postcranial bones can only be compared with each other and with STS 14 by estimating total bone lengths.

\section{(c) Indirect comparisons}

The head and greater part of the shaft of the STS 7 humerus are preserved. Broom, Robinson and Schepers ('50: 57) estimate a total bone length of about $300 \mathrm{~mm}(290$ 310 ). The humerus is associated with a scapula, a vertebra, and a large mandible. The mandible has a very large posterior dentition and the largest lower canine from Sterkfontein, suggesting the possibility that it is a male. Use of the Steele and McKern ('69) regression for a male humerus indicates an estimated length of $319 \pm 12$ $\mathrm{mm}$. The regression uses a maximum proximal-distal head diameter of $33.5 \mathrm{~mm}$ which I measured on the original specimen. Müller's proportions ('35) indicate a length of $293 \pm 17 \mathrm{~mm}$. Of the regressions, the Steele and McKern ('69) seems the most accurate, since the male average head diameter in the sample from which the regression was derived is $33.4 \mathrm{~mm}$. Since Broom, Robinson and Schepers ('50) indicate a maximum estimate of $310 \mathrm{~mm}$, and because this fits well within the expected error of the regression, I will use an estimate of $310 \mathrm{~mm} \pm 15 \mathrm{~mm}$ for the length of STS 7.

The dimensions of the distal femur fragments were, in most cases, considerably 
less than those of modern femurs of the lengths calculated by the Steele and McKern ('69) regression. It was not possible to find femurs with dimensions as small as the two distal ends from Sterkfontein. In most dimensions the bones fall well below the European ranges of variation (Ingalls, '24; Parsons, '13). Le Gros Clark ('47) points out that the bicondylar breadth of TM 1513 is best matched by a 12-year-old from his European collection (47: 327). Only the smallest of four Bushman femurs was comparable to it. For these reasons, I believe that the lengths calculated from the Steele and McKern ('69) regression are not accurate for TM 1513 and STS 34!

Length estimates for the two distal fragments are therefore based on a reconstruction of ER 993, a new femur from East Rudolf, made by Dr. A. Walker (73). ER 993 is complete from the distal end to the base of the lesser trochanter. Walker found that the dimensions of ER 993 just below the lesser trochanter closely matched the Olduvai australopithecine proximal end $\mathrm{OH} 20$. Consequently, he used $\mathrm{OH} 20$ to reconstruct the missing shaft and neck. The head reconstruction seems reasonable. A comparison of head circumference to the circumference below the lesser trochanter places ER 993 within the Swart- krans range. The reconstructed head is relatively smaller than those of the smallest two femurs, STS 14 and ER 738, and is considerably smaller for this ratio than the values for Homo. Walker (73) points out that the new femur closely approximates the known morphological pattern of other australopithecine specimens. Its relative shaft robusticity also fits the known pattern. For instance, as table 4 indicates, if the proportion of circumference below the lesser trochanter to total length for ER 993 is used to predict the total length of STS 14 from the corresponding circumference, the estimated value is $275 \mathrm{~mm}$, almost identical to the Lovejoy and Heiple reconstruction. In other words, this shaft circumference has the same ratio to total length in the only two specimens with reconstructed lengths.

Thus, it seems reasonable to use other dimensional proportions with length for estimating lengths of the Sterkfontein distal ends. The estimations are based on the only ratios available for any australopithecine. Table 4 indicates the results of these estimations based on two measurements of the distal ends. The first, distal articular surface breadth, was used because it gave the highest correlation with bone length in a sample of 75 femurs fom Libben, an

TABLE 4

Comparative measurements of the Walker reconstruction for ER 993 and the three Sterkfontein femurs. For ER 993, all measurements except length were taken on the original specimen. Length was measured on the reconstruction. Proportions of the ER 993 dimensions with reconstructed length serve as the basis for length estimates of the Sterkfontein specimens. Measurements are given in millimeters

\begin{tabular}{|c|c|c|c|c|c|c|}
\hline & \multicolumn{3}{|c|}{ ER 993} & \multicolumn{3}{|c|}{ STS 14} \\
\hline & \multicolumn{2}{|c|}{ Measurement } & $\begin{array}{l}\text { Length } \\
\text { proportion }\end{array}$ & \multicolumn{2}{|c|}{ Measurement } & $\begin{array}{l}\text { Length } \\
\text { estimation }\end{array}$ \\
\hline \multirow{3}{*}{$\begin{array}{l}\text { Circumference } \\
\text { below lesser } \\
\text { trochanter }\end{array}$} & 91 & & 4.05 & 68 & & 275 \\
\hline & \multicolumn{2}{|c|}{ ER 993} & \multicolumn{2}{|c|}{ TM 1513} & \multicolumn{2}{|c|}{ STS 34} \\
\hline & Measurement & $\begin{array}{l}\text { Length } \\
\text { proportion }\end{array}$ & Measurement & $\begin{array}{l}\text { Length } \\
\text { estimation }\end{array}$ & Measurement & $\begin{array}{l}\text { Length } \\
\text { estimation }\end{array}$ \\
\hline $\begin{array}{l}\text { Distal arti- } \\
\text { cular surface } \\
\text { breadth }\end{array}$ & 63.5 & 5.76 & 55.6 & 322 & 57.0 & 328 \\
\hline $\begin{array}{l}\text { Proximal border } \\
\text { of in tercondylar } \\
\text { fossa to distal } \\
\text { end of bone }\end{array}$ & 35.3 & 10.38 & 30.0 & 311 & 31.3 & 324 \\
\hline
\end{tabular}


amerind site. The second, proximal border of the intercondylar fossa to the distal border of the bone, was used because Steele and McKern found good correlation values with bone length, and use it in their fragmentary reconstruction regressions. In both cases, the proportions of these dimensions with the length of ER 993 were calculated, and then this proportion was used to estimate lengths for the Sterkfontein specimens. The estimates for each bone are within $3 \%$ of each other. At the maximum, the expected lengths for TM 1513 and STS 34 are 320 and $330 \mathrm{~mm}$. I doubt that TM 1513 is the appropriate size for the STS 14 femur, as Robinson ('72:124) suggests.

\section{(d) Height reconstructions}

The three femur reconstructions give length estimates of 280,320 , and $330 \mathrm{~mm}$. The only way of comparing these with the reconstructed humerus length is by estimating body height for all four individuals, and then comparing the estimated heights. As Wells ('63) points out, height regressions tend to be least accurate above and below the range of the population from which they were calculated. Because the gracile specimens are small, a regression for a small population was sought. The height regression best meeting the criteria considered was published by Genovés ('67). He calculated a set of regression formulae for Mesoamericans in the form of tables which were based on specimens that extend well into the australopithecine range of variation. Using these regressions, lengths were calculated for the four specimens discussed. It should be mentioned that the stature calculated for STS 14 is not the same as that reported by Lovejoy and Heiple ('70). This is because these authors used Manouvrier's tables for height reconstruction from femur length. I prefer the Mesoamerican data for reasons already discussed and because of the general inaccuracy in Manouvrier's results (Pearson, 1898) when applied to very large or very small individuals.

The female regression was used for STS 14 , since the pelvis can be sexed as female. The male regression was used for STS 7 because of the very large canine in the associated mandible. The other bones could not be sexed, and the average of the male and female regressions is reported.
TABLE 5

Limb bone length estimates and stature calculations

\begin{tabular}{llcc}
\hline Bone & Specimen & $\begin{array}{c}\text { Estimated } \\
\text { length }\end{array}$ & $\begin{array}{c}\text { Calculated } \\
\text { stature }\end{array}$ \\
\hline \multirow{3}{*}{ Femur } & & $m m$ & $\mathrm{~cm}$ \\
& STS 14 & 280 & 122 \\
& STS 34 & 330 & 135 \\
Humerus & TM 1513 & 320 & 133 \\
& STS 7 & 310 & 161 \\
& & Average & 138 \\
\hline
\end{tabular}

(e) Average height

Table 5 indicates the results of the height estimations. Should they be indicative of the South African gracile sample, the average height is $138 \mathrm{~cm}\left(4^{\prime} 6 \frac{1 / 2}{\prime \prime}\right)$, and the observed range is from $122 \mathrm{~cm}$ $\left(4^{\prime}\right)$ to $161 \mathrm{~cm}\left(5^{\prime} 4^{\prime \prime}\right)$.

I am fully aware of the limitations of the techniques used here. Reconstruction of limb bone lengths from fragments has never attained great accuracy. Reconstruction of height from these lengths was done using a regression calculated from a nonaustralopithecine population. These two factors must introduce error. In addition, the sample size is quite small. The average height is greater than the height of the single best preserved specimen, STS 14. However, there are some indications that this could be expected. The direct comparisons of vertebrae showed one individual, STS 73 , considerably larger than STS 14. In addition, the morphology of the pubis shows that the smallest femur, STS 14, belonged to a female. It is likely that males of the same sample are larger.

The height reconstructions assume that the australopithecines were bipedal, and the estimates are based on properties of the fragments which have the same biomechanical functions in any bipedal hominid. I believe the available evidence supports this assumption, indicating that australopithecines were striding hominids, fully adapted to the upright posture and striding gait characteristic of modern man (Dart, '57; Lovejoy and Heiple, '72; Heiple and Lovejoy, '71; Lovejoy, Heiple and Burstein, '73; Helmuth, '68).

Posture of the australopithecines also bears on the problem of the relative proportion of the arms and legs. If the gracile 
australopithecines had relatively long arms, height reconstructions based on the humerus will be too large. A bipedal posture with a striding gait argues against relatively long arms, but does not preclude them. It would not be impossible to reconstruct a striding hominid with relatively long arms and a robustly developed shoulder complex and hand facilitating a hanging adaptation in the trees which could go right along with a bipedal striding adaptation to the ground. Only one South African australopithecine specimen has fragments from both the arm and leg. This is the Kromdraai specimen TM 1517, where the distal end of the humerus can be compared with the talus. Broom and Schepers ('46: 114,118 ) point out that the humeral fragment and the talus both agree in size with a female bushman. Consequently, the ratio of one to the other should be about the same as in modern man. From other considerations, Helmuth ('68) also concludes that the proportions of arm length to leg length is human-like in the australopithecines. A recent study (Hamilton, '73) uses distal humerus and talus measurements best correlating with humerus and femur length to construct the humerustalus index which would be most indicative of the expected humero-femoral index. The humerus-talus index was compared with a large sample of Homo and Pan troglodytes. The ranges for the modern species do not overlap, and the Kromdraai ratio falls within the Homo range. In sum, the available evidence indicates that australopithecine arms have the relative length of Homo, and not of Pan.

The authors who have suggested relatively long arms for the australopithecines (Robinson, '72; Tattersall, '70; Pilbeam, '72) rely on the comparison of the STS 7 humerus with the STS 14 femur. However, STS 14 has the smallest of the three femurs from Sterkfontein, while the humerus is associated with the second largest Sterkfontein mandible. Such comparisons ignore individual variation.

Finally, it is important to attempt an estimation of the accuracy of the sample average. One possibility is to use the single specimen with both cranial and postcranial remains, STS 7 . The ratio of South African gracile australopithecine average tooth size to average height can be com- pared with the ratio of tooth size to height for STS 7. Using the average gracile summed posterior mandibular areas, the ratio of the averages is 0.62 , with the posterior area sum in $\mathrm{mm}^{2}$ and the height in millimeters. For STS 7, the ratio of the estimated maxillary posterior area sum to the height calculated from the humerus is 0.61 . Consequently, I believe that the parameters calculated here are of the correct order of magnitude, and estimate an approximately $4 \mathrm{~cm}$ standard error of the mean.

What effect would other alternatives have on the sample estimate? The two other alternatives would be to use the femurs alone, which would give an average height of $130 \mathrm{~cm}$, or to use the most complete specimen alone, which would give a height of $122 \mathrm{~cm}$. These alternatives involve fewer assumptions, and both suggest smaller heights. Finally, if the humerus of the australopithecines is found with new discoveries to be relatively longer than that of Homo, the stature estimation based on STS 7 will be too large. In sum, $138 \mathrm{~cm}$ must be taken as a maximum estimate based on the present sample.

\section{(f) Estimation of average weight}

The magnitude of australopithecine height comes close to that of several pigmy groups. The average Ituri height $(n=892)$, calculated from data reported by Gusinde ('48) as the average of male and female means, is $140.5 \mathrm{~cm}$. The two pigmy groups reported by Roberts ('53) average 142.2 $\mathrm{cm}$ for 147 individuals. Finally, two other pigmy groups, the Ofay and the Vieux Kilo, average $142.0 \mathrm{~cm}$ for 48 specimens (Mann, Roels, Price and Merrill, '62). The average weights for the Ituri, Ofay, and Vieux Kilo are $37.7 \mathrm{~kg}, 40.0 \mathrm{~kg}$, and 37.3 $\mathrm{kg}$. From these data, a ratio of height to weight can be calculated. The three corresponding ratios are $3.7,3.6$, and 3.8. The modal ratio of 3.7 belongs to the sample with the largest number of individuals. Because this is the only datum available for a population of small bipedal hominids, it will be used in estimating the average weight of gracile australopithecines. From the 3.7 ratio, an estimated average weight of $37.3 \mathrm{~kg}(82 \mathrm{lbs})$ corresponds to the average gracile australopithecine height. Most previous estimates have been somewhat 
smaller, closer to 40 or 50 pounds. These, however, are based on STS 14 and while they are probably correct for that specimen, it lies at the small end of the range of variation. The australopithecines were likely more robust in build than modern populations, so an estimate of $40 \mathrm{~kg}$ could be taken as a maximum estimate of the average, based on an estimated $138 \mathrm{~cm}$ height.

\section{GRACILE AUSTRALOPITHECINE TOOTH SIZE}

(a) Sources of the data

The posterior maxillary tooth measurements used derive from a number of sources. I measured all australopithecine teeth (see APPENDIX) as well as the East African Homo erectus specimens. C. L. Brace measured the Krapina Neandertals. All other hominid teeth come from sources given in another publication (Wolpoff, 71a). The Homo sapiens sample, largely measured by me, represents a worldwide distribution. The chimpanzees consist of specimens from the Hamann-Todd collection which I measured, specimens from the Harvard Peabody Museum and the Museum of Comparative Zoology measured by C. L. Brace, and specimens reported by Pilbeam ('69). Gorilla specimens from the Hamann-Todd collection were measured by Mr. Paul E. Mahler and myself. To these were added individuals reported by Pilbeam ('69) and Booth ('71).

A complete posterior area sum can be made for only five gracile australopithecine maxillas. However, it is possible to make an accurate estimate of the summed posterior maxillar area in four other specimens. This is because of the very close relationship between summed posterior areas in mandible and maxilla. Using 164 specimens of Homo sapiens representing a worldwide sample, I calculated the ratio of maxillary to mandibular summed posterior area. This ratio was 1.06 with a very low coefficient of variation of 3.1. In addition, the ratio can be calculated for a gracile australopithecine - STS 52. This ratio is 1.07. Because the variability of the Homo sapiens sample was quite low, it seemed reasonable to use the 1.07 multiplier to estimate maxillary posterior areas from the four complete gracile australopithecine mandibles. Consequently, the total gracile australopithecine sample is nine. Table 8 gives the summed posterior areas.

\section{(b) Size of the individual teeth}

Table 6 shows the statistics for individual posterior maxillary tooth areas, and table 7 gives the frequency distribution for each tooth. The total number of teeth used (90) is over $150 \%$ the sample size used by Robinson in 1956. In most cases, the average areas are larger than those calculated from Robinson's data ('56). In $\mathbf{~ m m}^{2}$, the difference is 0 for $\mathrm{PM}^{3}, 5$ for $\mathrm{PM}^{4}, 5$ for $\mathrm{M}^{1}$, 8 for $\mathrm{M}^{2}$, and 13 for $\mathrm{M}^{3}$. These differences increase posteriorally. $\mathrm{M}^{3}$ and $\mathrm{M}^{2}$ are almost identical, rather than $\mathrm{M}^{3}$ being considerably smaller as initially thought. $\mathrm{M}^{3}$ is larger than $\mathrm{M}^{2}$ in 2 of the 7 specimens for which the comparison is possible.

The frequency distributions indicate some evidence of bimodality for tooth areas of the molars.

With the exception of $\mathrm{M}^{3}$, all of the ranges overlap with a very large sample of Homo sapiens (Wolpoff, '71a). On the other hand, the megadont condition of our Lower Pleistocene ancestors is clearly outlined by a comparison of the gracile australopithecine posterior areas with areas of the corresponding teeth in Homo sapiens. $\mathrm{PM}^{3}$ in the graciles is larger than Homo sapiens by $52 \%, \mathrm{PM}^{4}$ by $74 \%, \mathrm{M}^{1}$ by $41 \%, \mathrm{M}^{2}$ by $87 \%$, and $\mathrm{M}^{3}$ by $114 \%$.

TABLE 6

Statistical parameters for individual South African gracile australopithecine posterior maxillary tooth areas in $\mathrm{mm}^{2}$

\begin{tabular}{|c|c|c|c|c|}
\hline Tooth & $\begin{array}{c}\text { Sample } \\
\text { size }\end{array}$ & Mean & Range & $\begin{array}{c}\text { Coefficient } \\
\text { of } \\
\text { variation }\end{array}$ \\
\hline PM $^{3}$ & 14 & 111 & $92-129$ & 9.5 \\
\hline PM 4 & 12 & 121 & $100-161$ & 14.7 \\
\hline$M^{1}$ & 20 & 178 & $142-220$ & 10.6 \\
\hline$M^{2}$ & 19 & 221 & $177-288$ & 13.4 \\
\hline $\mathrm{M}^{3}$ & 15 & 219 & $177-318$ & 20.3 \\
\hline
\end{tabular}


TABLE 7

Frequency distribution in absolute numbers of South African gracile australopithecine posterior maxillary tooth areas. Areas are in $\mathrm{mm}^{2}$

\begin{tabular}{cccccc}
\hline Areas & PM $^{3}$ & PM $^{4}$ & M $^{1}$ & M $^{2}$ & M $^{3}$ \\
\hline $81-90$ & 0 & 0 & & & \\
$91-100$ & 2 & 1 & & & \\
$101-110$ & 4 & 2 & & & \\
$111-120$ & 5 & 5 & & & \\
$121-130$ & 3 & 1 & & & \\
$131-140$ & 0 & 1 & 0 & & \\
$141-150$ & & 1 & 1 & & \\
$151-160$ & & 0 & 2 & 0 & 0 \\
$161-170$ & & 1 & 3 & 2 & 1 \\
$171-180$ & & 0 & 6 & 1 & 2 \\
$181-190$ & & & 5 & 2 & 4 \\
$191-200$ & & & 0 & 1 & 2 \\
$201-210$ & & & 2 & 4 & 2 \\
$211-220$ & & & 0 & 0 & 1 \\
$221-230$ & & & & 5 & 0 \\
$231-240$ & & & & 1 & 0 \\
$241-250$ & & & & 2 & 0 \\
$251-260$ & & & & 0 & 1 \\
$261-270$ & & & & 1 & 0 \\
$271-280$ & & & & 0 & 0 \\
$281-290$ & & & & & 0 \\
$291-300$ & & & & & 0 \\
$301-310$ & & & & & 0 \\
$311-320$ & & & & & \\
$321-330$ & & & & & \\
$331-340$ & & & & & \\
$341-350$ & & & & & \\
\hline
\end{tabular}

(c) Posterior maxillary area sums

Nine gracile specimens were used for the summation of areas in the posterior maxillary teeth. As discussed, four of these are estimated from posterior mandibular area sums as shown in table 8 . Table 9 indicates the statistical parameters of gracile australopithecine posterior maxillary area sums, and compares these with similar data for Homo erectus, Homo sapiens, and the African apes. The average for the nine specimens is $871 \mathrm{~mm}^{2}$. The sum of the averages for the individual teeth (see table 6) is 850 $\mathrm{mm}^{2}$. The average of the maxillary posterior areas is within $2.6 \%$ of the sum of the individual averages. So close an agreement is encouraging. The six Sterkfontein specimens by themselves average $892 \mathrm{~mm}^{2}$.

The gracile australopithecine range of variation is undoubtedly greater than these 9 specimens indicate. As table 9 shows, the largest specimen is about double the size of the smallest for men, gorillas, and chimpanzees. Expressed another way, the total range represents 5.7 standard deviations in Homo sapiens, 5.2 standard deviations in Pan gorilla, and 6.4 standard devia-
TABLE 8

Summed maxillary posterior areas $\left(P^{3}-M^{3}\right)$ for the five South African gracile maxillas. Four summed mandibular posterior areas are given, with the corresponding estimated maxillary areas, based on a 1.07 multiplier. All measurements are in $\mathrm{mm}^{2}$

\begin{tabular}{lccc}
\hline & & \multicolumn{2}{c}{$\begin{array}{c}\text { Estimated } \\
\text { Summed pos- }\end{array}$} \\
& $\begin{array}{c}\text { Summed pos- } \\
\text { summed pos- } \\
\text { lary area }\end{array}$ & $\begin{array}{c}\text { sumior man- } \\
\text { dibular area }\end{array}$ & $\begin{array}{c}\text { terior maxil- } \\
\text { lary area }\end{array}$ \\
\hline STS 17 & 799 & & \\
STS 52 1 & 822 & & \\
TM 1511 & 843 & & \\
TM 1514 & 864 & & \\
MLD 9/12 & 805 & 770 & 824 \\
MLD 18 & & 806 & 863 \\
MLD 40 & & 921 & 986 \\
STS 7 & & 974 & 1040 \\
STS 34 & & 9 & \\
\hline
\end{tabular}

1 Average of left and right.

tions in Pan troglodytes. If we use $850 \mathrm{~mm}^{2}$ as the average posterior area and the intermediate 5.7 standard deviation value of Homo sapiens, the expected range for the South African gracile sample would be 610 $\mathrm{mm}^{2}$ to $1090 \mathrm{~mm}^{2}$, or roughly 600 to 1100 $\mathrm{mm}^{2}$. Since the sum of the posterior averages is based on a larger sample size, I propose to use $850 \mathrm{~mm}^{2}$ to represent average summed posterior area in subsequent calculations. This is a minimum value. Since the height and weight estimates are maximum values, ratios of tooth size to body size will be minimized, because the numerator is minimized while the denominator is maximized.

Given this estimated average and range for gracile australopithecine posterior area, there are two questions to be considered. First, how does the area sum distribution compare with other hominids? On the average, the gracile australopithecines have posterior area sums close to $142 \%$ the size of Homo erectus, and $170 \%$ the size of a worldwide sample of Homo sapiens. While tooth size is considerably larger, body size is about $50 \%$ of the Homo sapiens average. A comparison holding body size constant can be made. A tribe of Bushmen with a body size average only slightly larger than the gracile australopithecines (Slome, '29) has a sum of posterior maxillary area averages of $406 \mathrm{~mm}^{2}$ (Drennan, '29). The area sum is a full $210 \%$ greater in the gracile australopithecines! As table 9 shows, the gracile australopithecines are completely outside the 
range of variation of Homo erectus, Neandertals, and modern man. The two largest Homo specimens, both belonging to Homo erectus, have areas of $698 \mathrm{~mm}^{2}(\mathrm{OH} 13)$, and $725 \mathrm{~mm}^{2}$ ("Pithecanthropus" 4). These are somewhat below the gracile australopithecine minimum. Thus, there is a metric gap between the gracile australopithecines and all subsequent hominids. With so clear a distinction between the australopithecines and later hominids, I believe the time is past when authors can picture chimpanzee and human posterior dentitions and suggest that because of the sim- ilarity in size and morphology no important dental evolution occurred in the Pleistocene (e.g., Washburn, '68: 33-34 and fig. 19).

The second question to be considered is how the maxillary grinding area of the graciles compares with that of the African apes. Table 10 shows that the graciles have almost double the grinding area of the chimpanzees, although they have about the same body weight. As tables 9 and 10 indicate, there is absolutely no overlap between the two taxa. This contrast is striking.

TABLE 9

Statistical parameters of the posterior maxillary tooth area sums in $\mathrm{mm}^{2}$ for Homo sapiens, Homo erectus, the African apes, South African and gracile australopithecines. $\mathrm{CV}$ is the coefficient of variation

\begin{tabular}{|c|c|c|c|c|c|}
\hline Area $\left(\mathrm{mm}^{2}\right)$ & $\begin{array}{c}\text { South African } \\
\text { Gracile Australo- } \\
\text { pithecine }\end{array}$ & Homo erectus & Neandertal & $\begin{array}{l}\text { Extant } \\
\text { Homo } \\
\text { sapiens }\end{array}$ & Chimpanzee \\
\hline $\begin{array}{r}201-250 \\
251-300 \\
301-350 \\
351-400 \\
401-450 \\
451-500 \\
501-550 \\
551-600 \\
601-650 \\
651-700 \\
701-750 \\
751-800 \\
801-850 \\
851-900 \\
901-950 \\
951-1000 \\
1001-1050 \\
1051-1100 \\
1101-1150\end{array}$ & $\begin{array}{r}0 \\
11 \\
44 \\
22 \\
0 \\
11 \\
11 \\
0\end{array}$ & $\begin{array}{r}0 \\
50 \\
17 \\
0 \\
17 \\
17 \\
0\end{array}$ & $\begin{array}{r}0 \\
7 \\
27 \\
20 \\
20 \\
20 \\
7 \\
0\end{array}$ & $\begin{array}{r}0 \\
1 \\
3 \\
21 \\
31 \\
24 \\
10 \\
5 \\
4 \\
1 \\
0\end{array}$ & $\begin{array}{r}0 \\
3 \\
29 \\
43 \\
18 \\
5 \\
1 \\
1 \\
0\end{array}$ \\
\hline
\end{tabular}

1 Includes maxillas and maxillary measures inferred from mandibles.

TABLE 10

Frequency distribution in percentiles of posterior maxillary tooth area sums in South African gracile australopithecines, Homo erectus, Neandertals (early Homo sapiens), postPleistocene Homo sapiens, and Pan troglodytes. Areas are in $\mathrm{mm}^{2}$

\begin{tabular}{|c|c|c|c|c|}
\hline & Mean & Range & $\begin{array}{l}\text { Sample } \\
\text { size }\end{array}$ & $\mathrm{CV}$ \\
\hline & $m m^{2}$ & & & \\
\hline Homo sapiens & 501 & $307-710$ & 238 & 14.2 \\
\hline Neandertals & 544 & $439-685$ & 15 & 13.1 \\
\hline Homo erectus & 601 & $529-725$ & 6 & 14.6 \\
\hline \multicolumn{5}{|l|}{$\begin{array}{c}\text { South African Gracile } \\
\text { Australopithecines }\end{array}$} \\
\hline & 826 & $799-864$ & 5 & 3.3 \\
\hline \multicolumn{5}{|l|}{$\begin{array}{l}\text { (b) Maxillas and } \\
\text { Maxillary measures }\end{array}$} \\
\hline inferred from mandibles & 871 & $799-1040$ & 9 & 9.6 \\
\hline Pan gorilla & 1011 & $744-1481$ & 331 & 14.0 \\
\hline Pan troglodytes & 475 & $371-692$ & 259 & 10.5 \\
\hline
\end{tabular}


As table 9 shows, the graciles have posterior maxillary dentitions about $84 \%$ as large as gorillas, although they have only about $31 \%$ of the body weight. Table 11 compares the frequency distributions for gracile australopithecines and gorillas. A full $64 \%$ of the gorillas overlap the range of gracile australopithecine variation. Every one of the gracile australopithecines falls within the gorilla range of variation.

\section{(d) Relative tooth size}

Posterior tooth size is best considered relative to body weight. There are two reasons for this. First, a weight calculation allows comparison with the African apes whereas a height comparison would not. Second, and probably of greater importance, posterior tooth size is related to diet and consequently a ratio with weight would maximize dietary differences by indicating the amount of mastication used to maintain a given body size.

A ratio of summed maxillary posterior area in $\mathrm{mm}^{2}$ divided by body weight in kilograms was calculated. This ratio, a measure of the tooth size to body size relationship, is 7.8 in gorillas, 7.4 in Homo sapiens, and 11.3 for chimpanzees. In other words, the range from 7.4 to 11.3 encompasses the spectrum of dietary differences

\section{TABLE 11}

Frequency distribution in percentiles of posterior maxillary tooth area sums in gorillas and South African australopithecines. Areas are in $\mathrm{mm}^{2}$

\begin{tabular}{ccc}
\hline Area & P. gorilla & $\begin{array}{c}\text { South African } \\
\text { gracile } \\
\text { australopithecine }\end{array}$ \\
\hline $601-650$ & 0 & \\
$651-700$ & 0 & 0 \\
$701-750$ & 1 & 11 \\
$751-800$ & 5 & 44 \\
$801-850$ & 5 & 22 \\
$851-900$ & 11 & 0 \\
$901-950$ & 17 & 11 \\
$951-1000$ & 14 & 11 \\
$1001-1050$ & 11 & 0 \\
$1051-1100$ & 11 & \\
$1101-1150$ & 9 & \\
$1151-1200$ & 5 & \\
$1201-1250$ & 5 & \\
$1251-1300$ & 2 & \\
$1301-1350$ & 1 & \\
$1351-1400$ & 1 & \\
$1401-1450$ & 1 & \\
$1451-1500$ & 1 & \\
\hline 1
\end{tabular}

1 Includes maxillas and maxill ary measures inferred from mandibles. shown by these three taxa. The minimum estimate of this ratio is about double for gracile australopithecines: 21.2. Jolly (personal communication) points out that the linear ratio of tooth size to body size is consistently smaller in males than in females for both chimpanzees and gorillas, and is smaller in gorillas than in chimpanzees. This would suggest that the relation of tooth size and body size is not strictly linear. He suggests, instead, relating tooth size to the $\log _{e}$ of body size, observing that such a ratio is almost the same in both sexes of the African apes, although different between the two taxa. The ratio of summed posterior maxillary area to the natural log of body weight in kilograms is 127 in chimpanzees, 208 in gorillas, and 119 in modern man. This ratio is considerably higher in the gracile sample: 230 at the minimum. Thus, the posterior tooth size of the South African gracile australopithecines is significantly larger than the African apes, relative to body size. It is about double that of modern man.

By either measure, gracile australopithecine tooth size is relatively larger than the three most closely related living hominoids. By either measure, gracile australopithecine tooth size is about double that of the hominoids with similar body weight, chimpanzees and modern man. They follow a pattern which has no living hominoid analog. These comparisons are based on a minimum ratio for the graciles. It seems that a significant difference in the amount of masticatory energy necessary per unit of ingested food value occurs between the graciles and Middle and Upper Pleistocene hominoids. If we assume that Homo erectus has roughly the same body mass as modern man, the $\log _{e}$ ratio is 143 , not even roughly intermediate between modern man and the South African graciles. In sum, the relative tooth size for the South African gracile australopithecines is anything but gracile.

\section{DISCUSSION AND CONCLUSIONS}

Based on the relative and absolute size of their posterior maxillary dentition, the South African gracile australopithecines seem to fit Jolly's model for a "phase 1" savanna-adapted hominid. Their dietary adaptation is quite unlike the African apes, Homo erectus, or Homo sapiens. Instead, 
the dentition suggests adaptation to a very heavily masticated diet. On the high veldt of South Africa this would presumably consist largely of cereal grains, although one would assume that culture bearing hominids would utilize all food resources available. Herein lies the crux of the discussion. Culture, with its heavy emphasis on learned behavior, makes it possible for hominids to exploit the widest range of resources. Extensive range, however, does not preclude intensive exploitation. Intensive focus on a particular food source is known today and in the past. For instance, at Choukoutien, a large percentage of the mammalian fauna consists of two species of red deer. Intensive cultivation of cereal grains characterizes the dietary niche for many living populations, and intensive exploitation of grains in the past is surely a viable possibility. Although unprocessed grains require heavy mastication for a primate dentition, the energy yield is high. For the South African gracile australopithecines, the size of the posterior dentition indicates a very special adaptation, and suggests by analogy to other primates utilizing similar environments that small hard objects form a selectively important component of the diet, for at least part of the year.

On the high veldt, cereal grains cannot be utilized all year. They are only available for three to four months. For the remainder of the year, other food sources were utilized. Presumably, then, selection for the large dentitions originated in this short period of intensive use. The success of the hominid adaptation lies in the versatility of learned behavior. For Lower Pleistocene hominids, this allowed intensive utilization of one type of food resource for part of the year, while at the same time it allowed the shift to other probably more extensive food sources when grains were not available. If living groups give any analogy, everything edible was probably used at one time or another.

The large posterior dentition, then, probably results from selection due to seasonal utilization of cereal grains. Grains may not be the only source of this selection. While Jolly suggests grains as the small objects most likely utilized in his "phase 1" hominid adaptation, I believe that roots make a likely addition. As Mann ('72) points out, there is little difference between a termiting stick and a digging stick. With a simple tool, roots are easily obtainable, and constitute another high energy food source causing heavy wear and thus providing additional selection for size. Only food sources such as these can explain the size of the posterior dentition.

How does this hypothesis relate to the archaeological evidence? Very little concrete information can be gained from the Transvaal caves. Brain has recently reopened the problem of whether the australopithecines were the hunters or the hunted ('70) by demonstrating that at least some of the bone accumulation, including hominids, at Swartkrans was due to leopard predation. Dart has long maintained that the Makapansgat accumulation shows signs of australopithecine predation. After reviewing the evidence, I believe that while Dart's explanation is possible, it is also possible that the unique fractures displayed by so many of the crania may be due to the density of the bone accumulations and the multiple collapses of the cave roof. Whatever the case, the evidence for extensive australopithecine hunting seems ambiguous. The full explanation for the cave accumulations probably involves numerous factors. It is not possible to determine which, if any, of the specimens were introduced by the australopithecines. The sole source of dietary inferences, at this time, must therefore come from the morphology of the australopithecines themselves.

There is extensive archaeological information from East Africa. However, it must be discussed with great caution. There is no guarantee that the same patterns apply to South Africa, although the similarity in the hominid samples and the favorable comparison of industries (Leakey, '70) are suggestive. In a recent review of Lower Pleistocene African occupation sites, Isaac (71) indicates the presence of some kill or butchery sites in East Africa, both at Olduvai (FLK NI) and East Lake Rudolf (Koobi Fora FxJj3). That these may be kill sites, and thus the result of hunting activity, would not be especially surprising. Chimpanzees hunt sporadically but with cyclic regularity (Teleki, '73; Van Lawick-Goodall, '68, '71), and there is far more game available on the savanna than there is in more wooded environments (Bourliére, 
'63) as measured by biomass density. Some hunting behavior must be expected in even the earliest hominids.

However, these sites may be only butchery occurrences. In both cases the bones of only a single large mammal are involved. Active and regular hunting of large mammals may not have occurred, as death could have been the result of other factors. The occurrence of numerous reptile, rodent, and frog bones in Bed I, Olduvai, may be revealing. Could these indicate the regular pattern of australopithecine hunting? Isaac concludes:

"There is at present no real way to assess the relative proportion of the total diet that accrued from gathering, hunting, and scavenging (p. 289)."

I suggest there is a way to make this assessment. If meat acquired by hunting or scavenging were a consistently important element in Lower Pleistocene hominid diet, one would expect to see some reduction in the total grinding area of the gracile australopithecines (Wolpoff, '71a). This is exactly what happens with the appearance of Homo erectus and the first archaeological evidence for large scale hunting. The dietary reconstruction suggested here presents the possibility that the dental reduction in Homo erectus is the result of a dietary shift which occurred as efficient organized hunting became possible. Australopithecine dietary reconstructions which suggest large scale intensive hunting do not allow this explanation of Homo erectus dental reduction.

In any event, the evidence indicates that the South African graciles maintained a tremendous masticatory apparatus, contrasting with both the African apes and with Homo. This does not preclude hunting, and indeed other indirect evidence suggests it. However, it implies that animal protein did not form a regular enough portion of the diet to supplant intensive utilization of grains and roots for at least part of the year.

The body part distribution at a number of sites suggests that the primary meat gathering activities of the East African populations could best be described as scavenging. Schaller ('72), in a recent appraisal of carnivore niches in the Serengeti, states:

"The fact that no large mammalian predator in the Serengeti subsists solely by scavenging suggests that hominids also would have found it difficult to do so unless they supplemented their diet with vegetal matter. . . There is no ecological room for a total scavenger (p. 68)."

This is precisely the niche I suggest for gracile australopithecines. There is no scavenger/gatherer stage in Jolly's scheme. The gracile australopithecines could probably best fit into his framework as "Phase $11 / 2$ " hominids with a stable scavenger/ gatherer adaptation to the savanna. Schaller (72) indicates that increased hunting activity would allow a significant decrease in the amount of vegetal foods utilized. This would lead to dental reduction, and fit the description of Jolly's "Phase 2." One could conjecture that the expanded cranial capacity which occurs in the late Lower and early Middle Pleistocene, with a concomitant increase in the complexity of learned behaviors ranging from tool technology to social organization, opened the door for organized hunting of large mammals. Hunting large ( $125+$ pounds) game is the only diurnal niche presently open for Serengeti carnivores (Schaller, '72).

The actual archaeological evidence is based on East African data. There is no way of directly determining whether scavenging also played a role in the South African gracile australopithecine adaptation. There are certain ecological similarities between the South and East African sites. While the similarities should not be overstated, both areas were savanna or open brush country. In terms of primate niches, both areas were then utilized by cercopithecoids and not by pongids. The same possibilities for scavenging were probably available for the South African populations, and it is certainly conceivable that they too utilized all available food sources.

In any event, the comparative morphology suggests that Robinson's dietary description of robust australopithecines also applied to the quite possibly misnamed graciles.

\section{ACKNOWLEDGMENTS}

I am deeply indebted to C. K. Brain and E. Voight of the Transvaal Museum, P. V. Tobias and A. Hughes of the Department of Anatomy, University of the Witwatersrand, and M. D. M. Leakey, M. D. Leakey, 
and R. E. F. Leakey of the National Museums of Kenya, Centre for Prehistory and Palaontology for permission to examine the fossil hominid material in their possessions, and for the help and encouragement given to me during my visit. I am grateful to A. Walker of the University of Nairobi for his help and guidance in identification of postcranial material. Finally, I thank D. W. Frayer and C. L. Brace for their extensive help in preparing this manuscript.

\section{LITERATURE CITED}

Altmann, S. A., and J. Altman 1970 Baboon Ecology. Bibliotheca Primatologica 12.

Booth, S. N. 1971 Observations on the teeth of the Mountain Gorilla (Gorilla gorilla beringei). Am. J. Phys. Anthrop., 34: 85-88.

Bourliére, F. 1963 Observations of the ecology of some large African mammals. In: African Ecology and Human Evolution. F. C. Howell and F. Bourliére, eds. Aldine, Chicago, pp. 43-54.

Brain, C. K. 1970 New finds at the Swartkrans australopithecine site. Nature, 225: 1112-1119.

Broek, A. J. P. v.d. 1938 Das Skelett einer weiblichen Efe-Pygmäe. Z. Morph. Anthrop., 40: 121-169.

Broom, R., J, T. Robinson and G. W. H. Schepers 1950 Sterkfontein Ape-Man Plesianthropus. Transvaal Mus. Mem., 4., Pretoria.

Broom, R., and G. W. H. Schepers 1946 The South African Fossil Ape-Men: The Australopithecinae. Transvaal Mus. Mem., 2., Pretoria.

Dart, R. A. 1957 The second adolescent (female) ilium of Australopithecus prometheus. J. Palaeontol. Soc. India, 2: 73-82.

Day, M. H. 1965 Guide to Fossil Man. World, Cleveland.

Drennan, M. R. 1929 The dentition of a Bushman tribe. Ann. S. Af. Mus., 24: 61-87.

Genovés, S. 1967 Proportionality of the long bones and their relation to stature among Mesoamericans. Am. J. Phys. Anthrop., 26: 67-78.

Gusinde, M. 1948 Urwaldmenschen am Ituri. Springer, Vienna.

Hamilton, M. 1973 Limb proportions of Australopithecus. In press.

Heiple, K. G., and C. O. Lovejoy 1971 The distal femoral anatomy of Australopithecus. Am. J. Phys. Anthrop., 35: 75-84.

Helmuth, H. 1968 Körperhöhe und Gliedmassproportionen der Australopithecinen. Z. Morph. An throp., 60: 147-155.

Ingalls, N. W. 1924 Studies on the femur. Am. J. Phys. Anthrop., 7: 207-255.

Isaac, G. 1971 The diet of early man: Aspects of archaeological evidence from Lower and Middle Pleistocene sites in Africa. World Archaeol., 2: 278-299.

Jolly, C. J. 1970a The seed-eaters: A new model of hominid differentiation based on a baboon analogy. Man, 5: 5-26.

- 1970b Hadropithecus: A lemuroid smallobject feeder. Man, 5: 619-626.

Jones, C., and J. S. Pi 1971 Comparative ecology of Gorilla gorilla (Savage and Wyman) and Pan troglodytes (Blumenbach) in Rio Muni, West Africa. Bibliotheca Primatologica 13.

van Lawick-Goodall, J. 1968 A preliminary report on expressive movements and communication in the Gombe stream chimpanzees. In: Primates: Studies in Adaption and Variability. P. C. Jay, ed. Holt, Rinehart, and Winston, New York, pp. 313-374.

1971 In the Shadow of Man. Houghton Mifflin, Boston.

Leakey, M. D. 1970 Stone artefacts from Swartkrans. Nature, 225: 1222-1225.

Lee, R. B. 1968 What hunters do for a living, or, how to make out on scarce resources. In: Man the Hunter. R. B. Lee and I. DeVore, eds. Aldine, Chicago, pp. 30-48.

LeGros Clark, W. E. 1947 Observations on the anatomy of the fossil Australopithecinae. J. Anat., $81 ; 300-333$.

Lovejoy, C. O., and K. G. Heiple 1970 A reconstruction of the femur of Australopithecus africanus. Am. J. Phys. Anthrop., 32: 33-40.

1972 Proximal femoral anatomy of Australopithecus. Nature, 235: 175-176.

Lovejoy, C. O., K. G. Heiple and A. H. Burnstein 1973 The gait of Australopithecus. Am. J. Phys. An throp., 38: 757-780.

Mann, A. 1968 The Paleodemography of Australopithecus. University Microfilms, Ann Arbor, 69-3652.

1972 Hominid and cultural origins. Man, $7: 379-386$.

Mann, G. V., O. A. Roels, D. L. Price and J. M. Merrill 1962 Cardiovascular disease in African pygmies. J. Chron. Dis., 15: 341-371.

Martin, R. 1928 Lehrbuch der Anthropologie. Fischer, Jena.

Müller, G. 1935 Zur Bestimmung der Länge beschädigter Extremitätenknocken. Anth. Anzeig., $12: 70-72$.

Napier, J. R., and P. H. Napier 1967 A Hand book of Living Primates. Academic Press, London.

Parsons, F. G. 1913 The characteristics of the English thigh bone. J. Anat. Lond., 48: 238-267.

Pearson, K. 1898 Mathematical contributions to the theory of evolution, part V. On the reconstruction of stature of prehistoric races. Phil Trans. Roy. Soc., 192: 169-244.

Pilbeam, D. R. 1969 Tertiary pongidae of East Africa: Evolutionary relationships and taxonomy. Peabody Mus. Nat. Hist., Yale U., Bul. 31.

1972 The Ascent of Man. Macmillan, New York.

Rahm, O. 1967 Observations during chimpanzee captures in the Congo. In: Progress in Primatology, D. Stark, R. Schneider and H. Kuh, eds. Fischer, Stuttgart, pp. 195-207.

Roberts, D. F. 1953 Body weight, race and climate. Am. J. Phys. Anthrop., 11: 533-558.

Robinson, J. T. 1956 The Dentition of the AustraIopithecinae. Transvaal Mus. Mem., 9., Pretoria.

1970 Two new early hominid vertebrae from Swartkrans. Nature, 225: 1217-1219.

1972 Early Hominid Posture and Locomotion. University of Chicago Press, Chicago.

Schaller, G. B. 1963 The Mountain Gorilla. Ecology and Behavior. University of Chicago Press, Chicago. 
1972 Are you running with me, hominid? Nat. Hist., $81(3): 61-68$.

Slome, D. 1929 The osteology of a bushman tribe. Ann. S, Af. Mus., 24: 33-60.

Steele, D. G., and T. W. McKern 1969 A method for assessment of maximum long bone length and living stature from fragmentary long bones. Am. J. Phys. Anthrop., $31: 215-228$.

Tattersall, I. 1970 Man's ancestors. Murray, London.

Teleki, G. 1973 The omnivorous chimpanzee. Sci. Am., 228(1): 32-42.

Walker, A. 1973 New Australopithecus femora from East Rudolf, Kenya. J. Hum. Ev., in press.
Washburn, S. L. 1968 The Study of Human Evolution. Condon Lecture, Oregon State System of Higher Education, Eugene.

Wells, L. H. 1963 Stature in earlier races of mankind. In: Science in Archaeology. D. Brothwell and E. Higgs, eds. Basic, New York, pp. 365 378.

Wolpoff, M. H. 1971 a Metric trends in hominid dental evolution. Case Western Reserve University Studies in Anthropology, 2. $1971 \mathrm{~b}$ Interstitial wear. Am. J. Phys. Anthrop., 34: 205-228.

$1971 \mathrm{c}$ A functional measure of tooth size. S. W. J. Anthrop., 27: 279-286.

Note added in proof: The problem of why the Steele and McKern regressions give femur lengths that are too long can now be resolved. The discovery of two complete femurs of Lower Pleistocene hominids at Lake Rudolf (ER 1472 and 1481), compared with the two reconstructed specimens discussed, indicate that joint surfaces at both proximal and distal ends are large relative to femur length when compared with modern populations. This is likely the result of relatively greater body weight in the Lower Pleistocene hominids when compared to modern man. Consequently, a different joint surface to body height regression in the fossil hominid sample is to be expected. 


\section{APPENDIX}

Individual South African gracile australopithecine tooth measurements for the maxillary cheek teeth. All measurements were taken by the author using techniques outlined in another publication ("71a). Error calculated from multiple measurements was under $2 \%$ for length, and about $1 \%$ for breadth

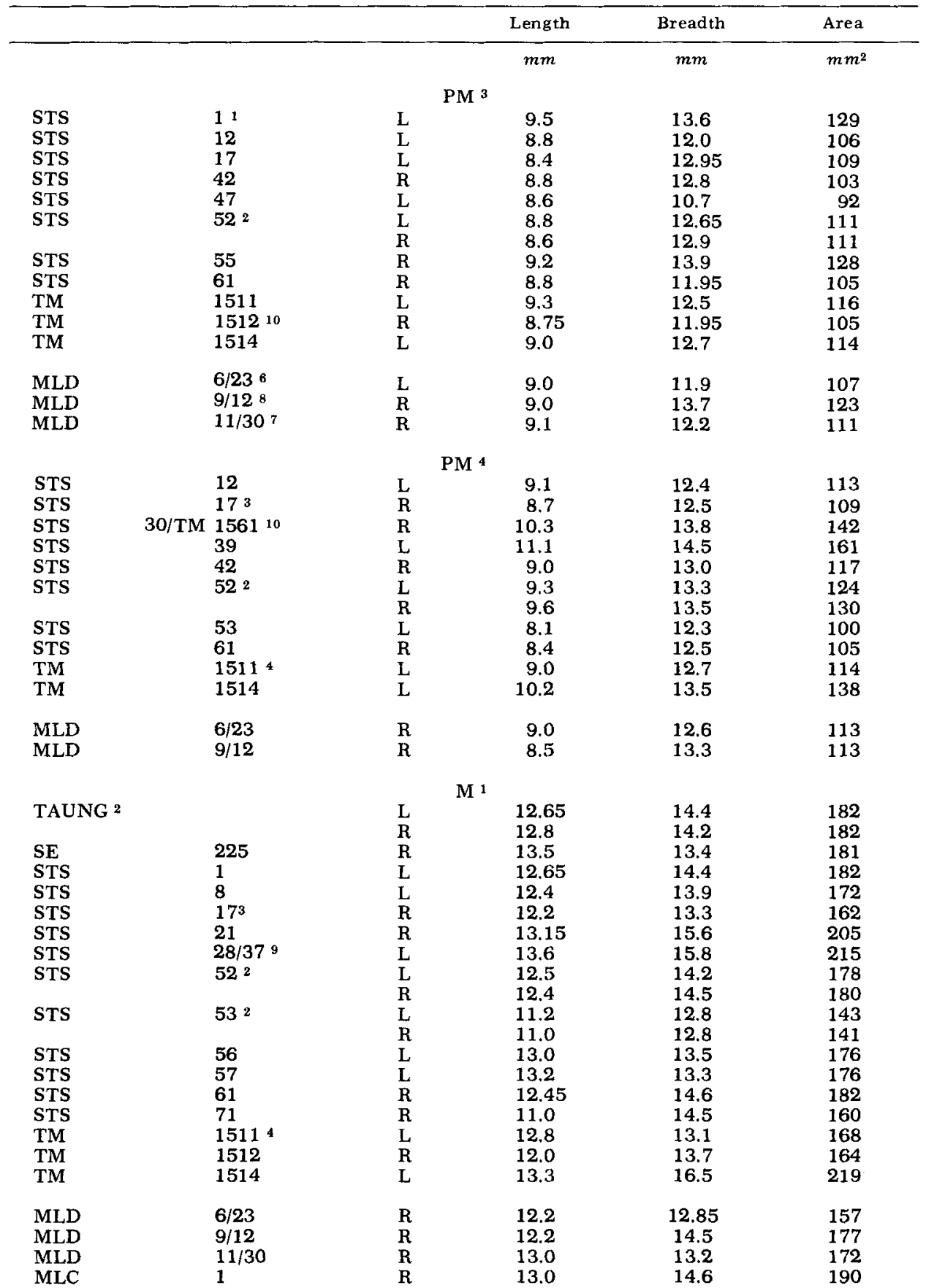


APPENDIX (continued)

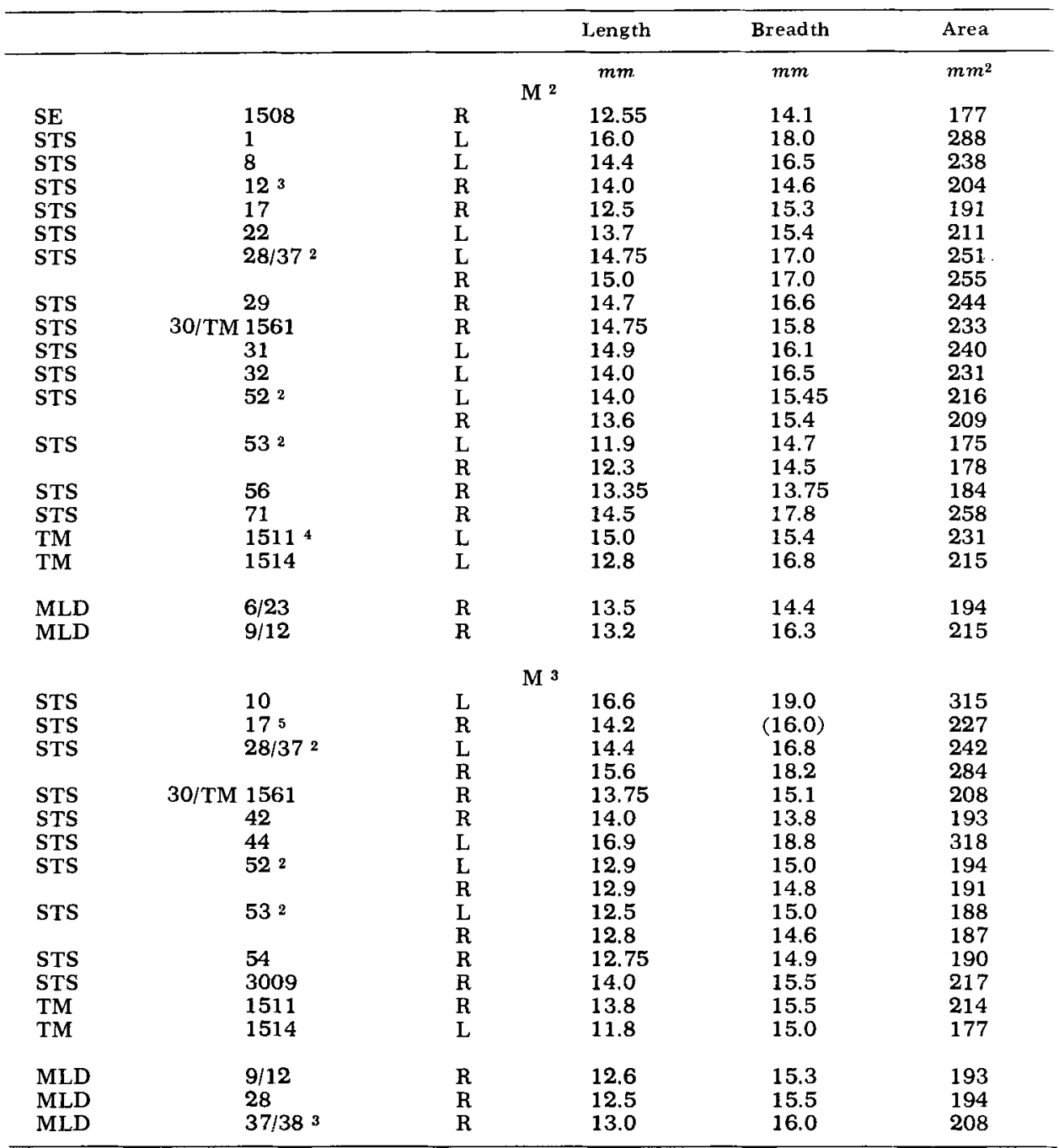

1 The more complete side is used.

2 Average of both sides used - sides are in equally good condition.

3 Right side used - left is more broken.

4 Left side used - right is more broken.

5 Breadth of this tooth was reconstructed. The break runs from a mesial point slightly lingual of the mesial pit, cutting distally and buccally. The central pit remains. In the STS 52 homologue the central pit is at the midpoint of the tooth and at the approximate area of greatest breadth. For STS 17, breadth was estimated as double the distance from the central pit to the lingual side.

6 MLD 6 and 23 are considered the same specimen. Size, wear, and color match, the canine sockets are the same size, and the catalog states identity.

${ }^{7}$ MLD 11 and 30 are the same specimen. The maxilla was broken open after discovery to remove the unerupted teeth.

${ }^{8}$ MLD 9 and 12 are considered the same specimen. The color matches and the wear on MLD 12 (M3) is about as different from $M^{2}$ on $M L D 9$ as $M^{2}$ is from $M^{1}$. The $6 \mathrm{~mm}$ of common interstitial wear face between $\mathrm{M}^{2}$ and $\mathrm{M}^{3}$ make a perfect fiit, and the catalog states identity.

${ }^{9}$ STS 28 and 37 are considered the same specimen. Coloration and wear are extremely close, and the cusp patterns on $\mathrm{M}^{2}$ and $\mathrm{M}^{3}$ are almost identical. The $\mathrm{M}^{3}$ on STS 28 has a large carabelli's cusp which accounts for the size difference with the STS $37 \mathrm{M}^{3}$.

10 STS 30 and TM 1561 are considered the same specimen. While the $M^{2}-M^{3}$ wear differential is not particularly great, the irregular contact facet makes a perfect fit. TM 1512 is not considered the same specimen, as suggested by Mann ('68) because the P4 of STS $30 / T M 1561$ is too large ( $\mathrm{L}=10.3 \mathrm{~mm}$ ) to fit in the $P^{4}$ gap in the TM $1512 \mathrm{maxilla}(\mathrm{L}=8.7 \mathrm{~mm})$. 